\title{
Artigos de periódicos científicos das áreas de informação no Brasil: evolução da produção e da autoria múltipla
}

Jayme Leiro Vilan Filho

Professor do Departamento de Ciência da Informação e Documentação (CID)

Held Barbosa de Souza

\section{Bibliotecária do Instituto de Ciências Biológicas (IB)}

\section{Suzana Mueller}

\section{Professora do Departamento de Ciência da Informação e Documentação (CID)}

Descreve a evolução da produção de 20 títulos de periódicos científicos brasileiros das áreas de Arquivologia, Biblioteconomia, Ciência da Informação e Documentação (1972-2006). Utiliza como fonte os registros de 3.706 artigos de periódicos científicos. Apresenta tabelas e gráficos com séries históricas de dados absolutos e percentuais relacionados com: número de artigos publicados, número de artigos em autoria múltipla (co-autoria), número de títulos de periódicos e número médio de artigos por periódico. Conclui que: a média anual de produção brasileira foi de 175 artigos (2000-2006); a produtividade média anual foi de 16 artigos/ano/periódico (2000-2006); o percentual de artigos em co-autoria em 2006 (49,16\%) está próximo do percentual de artigos em autoria única (50,84\%); e 85\% da co-autoria é de artigos com dois ou três autores (1972-2006). Conclui levantando algumas questões sobre possíveis causas desses resultados.

Palavras-chave: artigo de periódico; produção científica; autoria múltipla; co-autoria; Brasil. 


\section{Articles from Brazilian scientific journals in information areas: evolution of production and multiple authorship}

The evolution of the production in 20 Brazilian journals in Archive Science, Library and Information Science and Documentation is described (1972 to 2006). A total of 3,706 bibliographic records was examined. Tables and figures are presented, related to total number of published articles, total number of multiple authorship (co-authorship) articles, total number of journal titles, and average number of articles per journal. Final results show an yearly average production of 175 articles (2000 to 2006); yearly average productivity of 16 articles/year/journal (2000 to 2006); the percentage of articles in co-authorship is $49.16 \%$, close to the average percentage of single authorship articles, of $50.84 \%$ in 2006 , and $85 \%$ of co-authorships from articles with two or three authors (1972 to 2006). In conclusion, discussion about the possible causes of these results is presented.

Keywords: periodical article; scientific production; multiple authoring; co-authoring; Brazil.

Recebido em 25.03.2008 Aceito em 21.08.2008

\section{Introdução}

O fenômeno da colaboração entre cientistas para a produção do conhecimento científico não é novo na história da ciência moderna. De acordo com Meadows (1999 p. 107), apesar da prevalência de trabalhos realizados por pesquisadores que trabalhavam sozinhos, a Royal Society, no século 17, já via vantagens no trabalho em equipe como "um modo de promover novas pesquisas". Mas foi a partir do final do século 19 que a tendência para o trabalho científico colaborativo começou a ficar visível (DE HAAN, 1997), impulsionada pelo exemplo do método de ensino empregado pelo químico Justus von Liebig, da Escola de Química Orgânica na Universidade de Giessen, Alemanha, no século 19, que envolvia alunos como colaboradores hierarquicamente menores nas pesquisas por ele planejadas. Embora a prática do trabalho em colaboração, envolvendo pesquisadores experimentados e iniciantes, tenha se difundido na Europa no início do século 20, a pesquisa envolvendo equipes maiores e diversificadas ganhou mesmo impulso após a Segunda Guerra Mundial, 
especialmente nas chamadas big sciences e no desenvolvimento de tecnologias então emergentes (MEADOWS, 1999; CRAWFORD, 1966). A difusão da prática da pesquisa em colaboração, segundo Price (1976), é um dos fatores que contribuíram para o aumento contínuo do número de artigos científicos publicados.

A pesquisa em colaboração é incentivada atualmente por governos, agências de fomento, instituições de pesquisa e universidades, e prestigiada por editores, avaliadores e grupos científicos. Katz e Martin (1997, p. 01) atribuem esse prestígio à crença, difundida entre comunidades científicas e responsáveis por políticas científicas, de que "colaboração em pesquisa é uma coisa 'boa' para a ciência e que deve ser encorajada". Acredita-se que a colaboração reduz custos e aumenta os benefícios da pesquisa, inclusive a qualidade dos resultados. Mas Katz e Martin levantam questões sobre a veracidade dessa crença, especialmente em relação aos custos e benefícios. Entre seus argumentos, está a dúvida de que tais custos e benefícios possam ser de fato medidos, pois o próprio termo colaboração não é entendido por todos da mesma maneira. Baseados em uma revisão da literatura que incluiu 64 textos sobre o assunto, entre artigos, livros, proceedings e relatórios, publicados entre 1956 e 1998 (mais o conhecido artigo de Lotka de 1926, sobre produtividade científica), os autores mostram como o termo colaboração é usado para designar fenômenos diversos, mas que são tratados como se fossem a mesma coisa. Por exemplo, a colaboração pode dar-se entre indivíduos, grupos, setores da economia (tais como universidade e indústria) e países, pode persistir durante longo período ou ser eventual. E ainda, a natureza e magnitude da colaboração de cada participante podem variar de um simples insight à interação indispensável, e isso nem sempre é evidente. Cada tipo de colaboração apresenta, segundo aqueles autores, características específicas com efeitos possivelmente diferentes, as quais são ignoradas pelos estudiosos do fenômeno e pelas autoridades científicas.

Dentre os diversos tipos de colaboração, a autoria múltipla de artigos apresenta maior facilidade de mensuração e tem sido o indicador mais freqüentemente usado, a ponto de, frequentemente, o termo colaboração ser usado como sinônimo de autoria múltipla. Autoria múltipla pode ser definida como o texto científico assinado por mais de um autor. Embora mostre apenas que houve alguma colaboração, sem esclarecer detalhes tais como tipo ou intensidade de participação de cada autor, a autoria múltipla tem fornecido um indicador prático e preciso para verificar a existência de parcerias: se dois ou mais autores assinam um artigo, isso deve indicar algum tipo de colaboração; indica pelo menos que os autores concordaram em assumir a responsabilidade conjunta pelo que foi escrito.

As especificidades de cada área levam à adoção de maneiras diferentes de fazer e comunicar pesquisa, influenciando inclusive a predominância de autorias únicas ou múltiplas. Citando estudo de D. Lindsey, datado de 1978, sobre a publicação nas Ciências Sociais, Meadows (1999) relata diferenças encontradas por esse autor nos índices 
de autoria múltipla de algumas áreas: altos nas Ciências Naturais, como Química (83\%), Biologia (70\%) e Física $(67 \%)$, e mais baixos nas Ciências Sociais, como Serviço Social (25\%), Sociologia (25\%), Economia $(17 \%)$ e História (4\%). Mais recentemente, Mueller (1999) estudou alguns periódicos brasileiros da área de Economia, encontrando percentuais de $20 \%$ a $25 \%$ de autorias múltiplas. Há consenso que a colaboração ocorre com mais intensidade nas Ciências Naturais quando comparada às Ciências Sociais, mas De Haan (1997) notou que também nessas tem havido incremento de artigos com autorias múltiplas, embora textos assinados por autores únicos prevaleçam. Além das especificidades próprias de cada área, Price (1976, p.xi) reconheceu a influência da estrutura sócio-econômica de cada país sobre indicadores científicos, inclusive sobre a ocorrência de colaboração.

Seguindo a tendência geral das últimas décadas, o crescimento da produção de pesquisa em colaboração parece estar também ocorrendo no Brasil, especialmente nas ciências Naturais e Exatas. Meneghini (1996) mostrou, em estudo baseado em mais de 48 mil artigos brasileiros publicados em periódicos indexados pelo Institute of Scientific Information (ISI) entre 1981 e 1993, que houve incremento de $40 \%$ na quantidade de itens indexados no período, apesar do declínio de investimentos científicos no Brasil, que foi de menos 35\% entre 1986 e 1992. Oferece como explicação para esse fenômeno o aumento da pesquisa colaborativa, pois, enquanto 0 número de artigos não colaborativos permaneceu praticamente no mesmo patamar durante todo o período estudado (19811993), o número de artigos com autorias múltiplas cresceu substancialmente, tanto os textos com colaborações internacionais (pelo menos um autor com afiliação estrangeira), com quase $250 \%$, quanto os com colaborações nacionais, com pouco mais de $150 \%$. Além disso, 0 estudo de Meneghini sugere que a colaboração foi também responsável pelo alto impacto obtido pelos artigos brasileiros, pois a taxa de impacto dos artigos com colaboração internacional foi em média quatro vezes maior do que as obtidas por artigos não colaborativos, e a taxa de impacto dos artigos colaborativos nacionais foi de 1,6 em relação aos não colaborativos. Leta e Chaimovich (2002), em estudo semelhante, examinaram mais de 104 mil publicações de periódicos da base de dados Brazilian Science Indicators (BSI) do ISI, incluindo artigos, para analisar os efeitos do tamanho da produção científica e da colaboração internacional no aumento do reconhecimento da ciência brasileirai. Mas, ao contrário de Meneghini, concluem que a colaboração internacional sozinha não explica o grande crescimento da participação do Brasil no ISI a partir de 1993. Sugerem outros fatores que poderiam estar associados ao crescimento contínuo das publicações, como o aumento significativo de estudantes de pós-graduação e o esforço nacional de avaliação de programas de pós-graduação. Mas também notam que o reconhecimento das publicações em colaboração (citações recebidas) foi maior que o das publicações não colaborativas, sugerindo que a colaboração científica melhora a visibilidade internacional. Em outro estudo, Oliveira (2003) estudou trabalhos de pesquisadores de instituições da Amazônia brasileira 
e verificou total convergência entre esses dois fatores (autoria múltipla e visibilidade internacional): $100 \%$ do grupo de pesquisadores com alto índice de autoria múltipla obtiveram visibilidade internacional ótima, enquanto $90 \%$ do grupo de pesquisadores com baixo índice de autoria múltipla obtiveram visibilidade baixa ou nenhuma visibilidade.

O fenômeno da autoria múltipla tem sido estudado principalmente nas Ciências Naturais e da Saúde, como por exemplo, no citado artigo de Katz e Martin, talvez por ocorrer com maior freqüência nessas áreas. Mas, em anos mais recentes, de acordo com Meadows (1999), a tendência tem sido de crescimento da produção colaborativa em todas as áreas, no âmbito acadêmico e em empresas. O número de estudos sobre o fenômeno da autoria em colaboração nas Ciências Sociais também aumentou, inclusive sobre a colaboração na Ciência da Informação. Koehler (2001) examinou o Journal of the American Society for Information Science (JASIS), incluindo os fascículos do American Documentation (AD), analisando 2.257 artigos abrangendo 50 anos (1950-1999) de publicação, e chegou à conclusão de que os índices de autoria múltipla cresceram de $20 \%$ para quase $50 \%$, tendo os dos artigos assinados por dois autores aumentado de $10 \%$ para $30 \%$ e os dos artigos assinados por três ou mais autores de $10 \%$ para $20 \%$.

Estudos realizados no Brasil mostram que prevalecem as autorias únicas na literatura nacional da área, mas que o número de trabalhos em colaboração vem seguindo a tendência geral de crescimento. Mueller e Pecegueiro (2001) realizaram um levantamento dos artigos publicados na revista Ciência da Informação na década de 90. De um total de 248 artigos, identificaram 78,23\% com autorias únicas e $21,77 \%$ com autorias múltiplas. Bohn, (2003, p.7-8), em estudo posterior, examinou os fascículos de quatro revistas, publicados em 2001, encontrando índices mais baixos de autoria única $(58,15 \%)$, constatando, portanto, o aumento da autoria múltipla. Mas a distribuição dessas autorias múltiplas não se apresentou homogênea, tendo uma das revistas pesquisadas, a Ciência da Informação, concentrado o maior número, 54,85\%.

Em pesquisa mais recente, que considerou todos os fascículos até então publicados da revista Ciência da Informação (1972-2005), pode-se perceber a evolução do percentual de crescimento de autores/autorias múltiplas na área, no decorrer das três décadas de existência da revista, evoluindo de aproximadamente $20 \%$ nos anos 70 e 80 para $43,6 \%$ nos anos 90 e para 68,3\% na década atual (PINHEIRO, 2006). Tal crescimento também foi comprovado em estudo mais abrangente (SOUZA, 2006), realizado a partir de uma base de dados nacional que inclui 3.514 artigos de coleções completas de 18 títulos de periódicos científicos brasileiros das áreas de informação, cobrindo o período de 1972 a 2005 . A autora destaca que o crescimento da autoria múltipla não é regular, acentuandose a partir de 1996 , saindo do patamar de cerca de $20 \%$ dos artigos nos primeiros 24 anos (1972-1995), para cerca de 30\% dos artigos nos cinco anos seguintes (1996-2000) e passando para o patamar de cerca de $40 \%$ dos artigos nos cinco últimos anos (2001-2005) do estudo. Com exceção do estudo de Souza, os demais analisaram partes da literatura: ou se 
concentraram em apenas um periódico por um período mais ou menos longo (MUELLER e PECEGUEIRO, 2001; PINHEIRO, 2006), ou examinaram alguns periódicos cobrindo apenas alguns fascículos (BOHN, 2003). O presente estudo pretende expandir o estudo de Souza (2006), ampliando e atualizando a base de artigos com a inclusão de dois títulos, e apurando os critérios de seleção de textos para apenas artigos, excluindo palestras, relatos de experiência e outros. O objetivo é mostrar a evolução da produção de artigos com ênfase nas autorias múltiplas, nos periódicos científicos publicados no Brasil entre 1972-2006, nas áreas de informação, aqui entendidas por Arquivologia, Biblioteconomia, Ciência da Informação e Documentação. Mais especificamente, pretende-se responder às seguintes perguntas:

1. como se deu a evolução da produção de artigos em periódicos científicos brasileiros nas áreas de Arquivologia, Biblioteconomia, Ciência da Informação e Documentação, no decorrer das últimas três décadas, em termos de quantidade?

2. como evoluiu a produção de artigos em autoria múltipla no período observado (1972-2006)?

\section{Metodologia}

Este estudo é um levantamento de dados relacionados à ocorrência de autorias múltiplas em artigos publicados em revistas brasileiras nas áreas de informação. A fonte das informações foi a base de dados de artigos científicos de Arquivologia, Biblioteconomia, Ciência da Informação e Documentação - ABCID - implementada em CDS/ISIS for Windows (WinISIS), em formato de registro compatível com o MARC21 e desenvolvida por projeto específico no Departamento de Ciência da Informação e Documentação - CID - da Universidade de Brasília - UnB - a partir de 2001. A base ABCID contém 4.108 registros (dados de 02/08/2007) de referências bibliográficas de artigos de 22 títulos de periódicos científicos publicados no Brasil e em Portugal, entre títulos específicos e de áreas afins.

Os títulos brasileiros da base ABCID considerados neste estudo são:

1. Acervo: Revista do Arquivo Nacional;

2. Arquivística.net;

3. Arquivo \& Administração (exceto os fascículos de 2006);

4. Biblos;

5. Cadernos de Biblioteconomia;

6. Ciência da Informação;

7. DatagramaZero;

8. Em Questão.

9. Encontros Bibli;

10. Estudos Históricos;

11. Informação \& Informação;

12. Informação \& Sociedade: estudos;

13. Perspectivas em Ciência da Informação; 
14. Revista $A C B$;

15. Revista Brasileira de Biblioteconomia e Documentação;

16. Revista da Escola de Biblioteconomia da UFMG;

17. Revista de Biblioteconomia \& Comunicação;

18. Revista de Biblioteconomia de Brasília;

19. Revista Digital de Biblioteconomia e Ciência da Informação;

20. Transinformação.

Neste trabalho foram analisados os dados de autoria dos registros da ABCID referentes aos 3.706 registros de 20 títulos de publicações científicas brasileiras, cobrindo o período de 1972 a 2006. Os dados foram extraídos do WinISIS para arquivos do tipo texto (.txt), por meio do comando de impressão, e foram posteriormente inseridos no MS-Excel, onde foram produzidas as tabelas e gráficos para análise. Os registros são em sua maior parte de artigos científicos, embora existam registros de outra natureza como palestras, trabalhos de congressos entre outros, também publicados nos periódicos científicos. Importante observar que os dados relativos a ano, utilizados como referência de publicação dos fascículos neste estudo, foram obtidos da data de referência da publicação de cada fascículo, não correspondendo necessariamente aos anos de sua efetiva publicação. Além disso, quando estas datas se apresentam como intervalo, considera-se apenas o último ano, i.e. em 1999/2000 considera-se apenas 2000.

Este é um estudo bibliométrico. Katz e Martin notam que estudos de autorias múltiplas, embora não possam representar 0 fenômeno colaboração em toda a sua acepção, apresentam vantagens: os dados são invariantes e verificáveis; se prestam bastante para análises quantitativas e bibliométricas, podendo ser facilmente replicáveis por outros pesquisadores que tenham acesso aos mesmos dados; tornam possível o uso de amostras relativamente grandes, aumentando as chances de significação estatística. Borgman e Furner (2002, p. 4-5) também reconhecem na bibliometria "um poderoso conjunto de métodos e medidas para o estudo da estrutura e do processo de comunicação acadêmica." Quanto às bases de dados, são importantes como instrumentos de análise bibliométrica para se "traçar as tendências e o desenvolvimento da sociedade, das disciplinas científicas e das áreas de produção e consumo" (WORMELL, 1998, p.210).

Finalmente, as informações quantitativas apresentadas neste texto se referem ao número de artigos e seus percentuais, e não ao número de autorias (relação autor - artigo) nem ao número de autores (indivíduos ou instituições).

\section{Apresentação dos dados}

Nos 35 anos estudados, a produção total de artigos nos títulos examinados foi de 3.706 artigos. Os totais da produção anual de artigos nas áreas de informação no Brasil no período são apresentados na TAB. 1, em valores absolutos e percentuais, com detalhamento do número de 
artigos por tipo de autoria, única e múltipla, sendo esta última de dois a cinco autores (A2 a A5).

A produção começa com 35 artigos em 1972 e chega a 179 artigos em 2006. Pode-se notar claramente a diminuição gradativa dos valores percentuais de autoria única, que varia de 88,57\% em 1972 para 50,84\% em 2006, correspondendo ao aumento dos valores percentuais de autoria múltipla, que iniciam em $11,43 \%$ e chegam a $49,16 \%$ no mesmo período.

Em relação aos percentuais por tipo de autoria múltipla, as autorias em duplas (A2) ocorrem inicialmente com altos percentuais $(100 \% \mathrm{em}$ 1972), que vão diminuindo gradativamente, aproximando-se da metade do total de autorias múltiplas (56,8\%) em 2006, enquanto que os valores relativos a artigos com três ou mais autores apresentam valores bem mais modestos (ver Tab. 1).

TABELA 1 - Artigos de Periódicos Científicos das Áreas de Informação no Brasil por Tipo de Autoria e Ano de Publicação: valores absolutos e percentuais (1972-2006)

\begin{tabular}{|c|c|c|c|c|c|c|c|c|c|c|c|c|c|}
\hline ANO & ART. & $\mathrm{AU}$ & $\% A U$ & AM & $\% A M$ & $A 2$ & A2(\%) & A3 & A3(\%) & A4 & A4(\%) & A5 & A5(\%) \\
\hline 1972 & 35 & 31 & 88,57 & 4 & 11,43 & 4 & 100,0 & 0 & 0,0 & 0 & 0,0 & 0 & 0,0 \\
\hline 1973 & 67 & 63 & 94,03 & 4 & 5,97 & 1 & 25,0 & 2 & 50,0 & 1 & 25,0 & 0 & 0,0 \\
\hline 1974 & 48 & 41 & 85,42 & 7 & 14,58 & 6 & 85,7 & 1 & 14,3 & 0 & 0,0 & 0 & 0,0 \\
\hline 1975 & 57 & 44 & 77,19 & 13 & 22,81 & 10 & 76,9 & 3 & 23,1 & 0 & 0,0 & 0 & 0,0 \\
\hline 1976 & 47 & 41 & 87,23 & 6 & 12,77 & 2 & 33,3 & 3 & 50,0 & 1 & 16,7 & 0 & 0,0 \\
\hline 1977 & 98 & 67 & 68,37 & 31 & 31,63 & 13 & 41,9 & 11 & 35,5 & 4 & 12,9 & 3 & 9,7 \\
\hline 1978 & 65 & 49 & 75,38 & 16 & 24,62 & 11 & 68,8 & 1 & 6,3 & 3 & 18,8 & 1 & 6,3 \\
\hline 1979 & 75 & 65 & 86,67 & 10 & 13,33 & 5 & 50,0 & 0 & 0,0 & 4 & 40,0 & 1 & 10,0 \\
\hline 1980 & 69 & 47 & 68,12 & 22 & 31,88 & 14 & 63,6 & 5 & 22,7 & 2 & 9,1 & 1 & 4,5 \\
\hline 1981 & 87 & 70 & 80,46 & 17 & 19,54 & 8 & 47,1 & 8 & 47,1 & 0 & 0,0 & 1 & 5,9 \\
\hline 1982 & 62 & 47 & 75,81 & 15 & 24,19 & 9 & 60,0 & 5 & 33,3 & 0 & 0,0 & 1 & 6,7 \\
\hline 1983 & 91 & 75 & 82,42 & 16 & 17,58 & 12 & 75,0 & 1 & 6,3 & 1 & 6,3 & 1 & 6,3 \\
\hline 1984 & 72 & 60 & 83,33 & 12 & 16,67 & 7 & 58,3 & 5 & 41,7 & 0 & 0,0 & 0 & 0,0 \\
\hline 1985 & 86 & 69 & 80,23 & 17 & 19,77 & 12 & 70,6 & 5 & 29,4 & 0 & 0,0 & 0 & 0,0 \\
\hline 1986 & 84 & 65 & 77,38 & 19 & 22,62 & 9 & 47,4 & 6 & 31,6 & 1 & 5,3 & 1 & 5,3 \\
\hline 1987 & 97 & 74 & 76,29 & 23 & 23,71 & 14 & 60,9 & 5 & 21,7 & 3 & 13,0 & 1 & 4,3 \\
\hline 1988 & 85 & 66 & 77,65 & 19 & 22,35 & 11 & 57,9 & 8 & 42,1 & 0 & 0,0 & 0 & 0,0 \\
\hline 1989 & 136 & 106 & 77,94 & 30 & 22,06 & 13 & 43,3 & 8 & 26,7 & 5 & 16,7 & 3 & 10,0 \\
\hline 1990 & 113 & 77 & 68,14 & 36 & 31,86 & 23 & 63,9 & 9 & 25,0 & 3 & 8,3 & 1 & 2,8 \\
\hline 1991 & 67 & 50 & 74,63 & 17 & 25,37 & 9 & 52,9 & 7 & 41,2 & 1 & 5,9 & 0 & 0,0 \\
\hline 1992 & 70 & 53 & 75,71 & 17 & 24,29 & 11 & 64,7 & 5 & 29,4 & 1 & 5,9 & 0 & 0,0 \\
\hline 1993 & 87 & 66 & 75,86 & 21 & 24,14 & 16 & 76,2 & 3 & 14,3 & 0 & 0,0 & 2 & 9,5 \\
\hline 1994 & 81 & 69 & 85,19 & 12 & 14,81 & 7 & 58,3 & 3 & 25,0 & 1 & 8,3 & 0 & 0,0 \\
\hline 1995 & 100 & 80 & 80,00 & 20 & 20,00 & 15 & 75,0 & 2 & 10,0 & 2 & 10,0 & 0 & 0,0 \\
\hline 1996 & 149 & 112 & 75,17 & 37 & 24,83 & 26 & 70,3 & 7 & 18,9 & 1 & 2,7 & 2 & 5,4 \\
\hline 1997 & 138 & 104 & 75,36 & 34 & 24,64 & 16 & 47,1 & 12 & 35,3 & 5 & 14,7 & 1 & 2,9 \\
\hline 1998 & 152 & 101 & 66,45 & 51 & 33,55 & 34 & 66,7 & 9 & 17,6 & 7 & 13,7 & 0 & 0,0 \\
\hline 1999 & 162 & 110 & 67,90 & 52 & 32,10 & 31 & 59,6 & 9 & 17,3 & 6 & 11,5 & 3 & 5,8 \\
\hline 2000 & 189 & 118 & 62,43 & 71 & 37,57 & 41 & 57,7 & 17 & 23,9 & 6 & 8,5 & 5 & 7,0 \\
\hline 2001 & 150 & 87 & 58,00 & 63 & 42,00 & 38 & 60,3 & 13 & 20,6 & 4 & 6,3 & 5 & 7,9 \\
\hline 2002 & 172 & 113 & 65,70 & 59 & 34,30 & 29 & 49,2 & 19 & 32,2 & 4 & 6,8 & 5 & 8,5 \\
\hline 2003 & 188 & 123 & 65,43 & 65 & 34,57 & 43 & 66,2 & 15 & 23,1 & 4 & 6,2 & 0 & 0,0 \\
\hline 2004 & 186 & 100 & 53,76 & 86 & 46,24 & 56 & 65,1 & 16 & 18,6 & 6 & 7,0 & 1 & 1,2 \\
\hline 2005 & 162 & 90 & 55,56 & 72 & 44,44 & 48 & 66,7 & 14 & 19,4 & 4 & 5,6 & 3 & 4,2 \\
\hline 2006 & 179 & 91 & 50,84 & 88 & 49,16 & 50 & 56,8 & 21 & 23,9 & 9 & 10,2 & 2 & 2,3 \\
\hline Totais & 3.706 & 2.624 & 70,80 & 1.082 & 29,20 & 654 & 60,6 & 258 & 25,1 & 89 & 8,4 & 44 & 3,6 \\
\hline
\end{tabular}

ANO - Ano de publicação obtido nos fascículos dos periódicos, ART - Número de artigos publicados, AU Número de artigos em autoria única, AM - Número de artigos em autoria múltipla, A2 - Número de artigos com dois autores, A3 - Número de artigos com três autores, A4 - Número de artigos com quatro autores, A5 - Número de artigos com cinco autores. Os percentuais AU\% e AM\% são em relação ao número total de artigos publicados (ART) por ano, enquanto os percentuais $A 1(\%), A 2(\%), A 3(\%), A 4(\%)$ e $A 5(\%)$ são em relação ao total de artigos publicados em autoria múltipla (AM) por ano.

Fonte: base de dados ABCID em 2 de agosto de 2007. 
A evolução da produção e da distribuição dos tipos de autoria pode ser mais bem observada nos cinco gráficos seguintes.

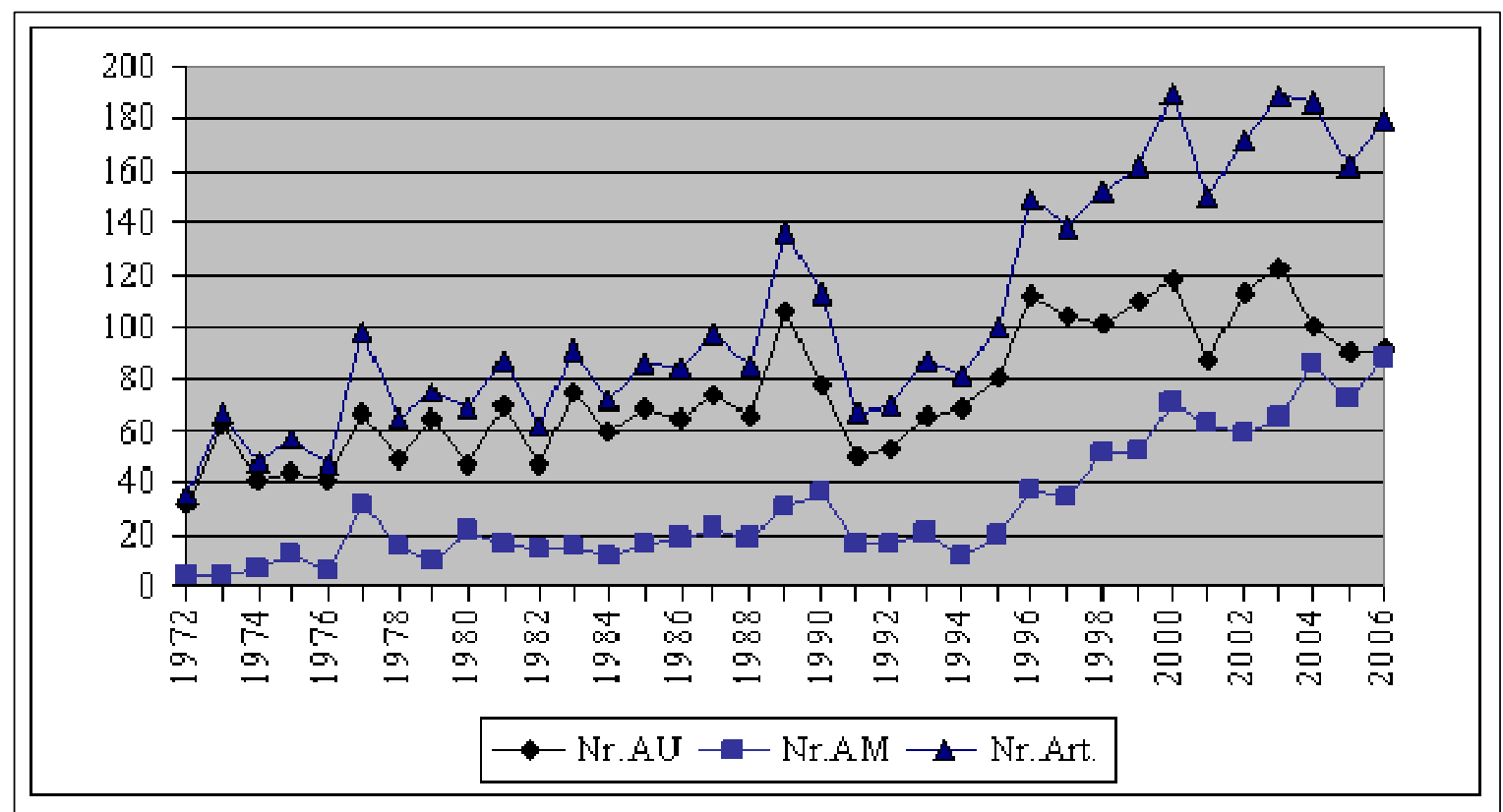

GRÁFICO 1 - Número de Artigos de Periódicos Científicos das Áreas de Informação no Brasil por Tipo de Autoria (1972-2006).

Fonte:Dados da pesquisa.

No GRÁF. 1 pode-se notar a evolução da produção de artigos em valores absolutos. O número total de artigos produzidos (linha superior Nr.Art.) cresce gradativamente até o início dos anos 1990, quando há uma queda abrupta, sendo o nível retomado apenas em 1996. Três irregularidades merecem destaque no GRÁF. 5:

a) a primeira é o pico de produção que ocorreu em 1977, decorrente da publicação de um número da Revista de Biblioteconomia de Brasília com muitos artigos do 8. Congresso Brasileiro de Biblioteconomia e Documentação (CBBD), ocorrido em Brasília em 1975;

b) a segunda é o pico de produção que ocorreu em 1989, decorrente da publicação de outro número da Revista de Biblioteconomia de Brasília, embora com menor impacto do que no primeiro pico, com trabalhos do 6 . Seminário sobre Publicações Oficiais Brasileiras (SPOB), ocorrido em Brasília em 1987; e

c) a terceira é a queda de produção ocorrida entre 1990 e 1994, que pode ser explicada em parte pela paralisação da Revista de Biblioteconomia de Brasília de 1991 a 1994, mas também pela redução da produção anual em todos os demais periódicos, sugerindo uma crise no setor editorial científico brasileiro, nas áreas de informação, neste período. Considerando que a partir de 
1996 os índices retomaram os valores anteriores e o nível de crescimento retomou sua tendência histórica, o fenômeno lembra a perturbação temporária causada pela Segunda Guerra Mundial no número de publicações científicas medidas por Price (1976, p.10-11).

A partir de 2000, a produção se estabiliza no patamar médio de 175 artigos/ano. Pode-se notar ainda no GRÁF. 1 que a evolução da autoria única (Nr.AU) acompanha a evolução da produção total de artigos (Nr.Art) até 1996, quando o número de artigos em autoria única (Nr.AU) se estabiliza na faixa entre 80 e 120 artigos/ano e começa a se distanciar da produção total de artigos (Nr.Art), enquanto aumenta o número de artigos em autoria múltipla (Nr.AM). Quanto à produção de artigos em autoria múltipla (Nr.AM), permanece quase 20 anos (1977-1995) próxima da faixa de 20 artigos por ano, até começar a aumentar em 1996 e chegar ao patamar médio próximo de 80 artigos/ano a partir de 2004.

O número de artigos em autoria única (91) e autoria múltipla (88) chegam a valores absolutos bem próximos em 2006. Tal fato pode ser mais bem observado no GRÁF. 2, onde a convergência entre as linhas que representam os percentuais de autoria única $(50,84 \%)$ e autoria múltipla $(49,16 \%)$ chega quase ao ponto de encontro em 2006.

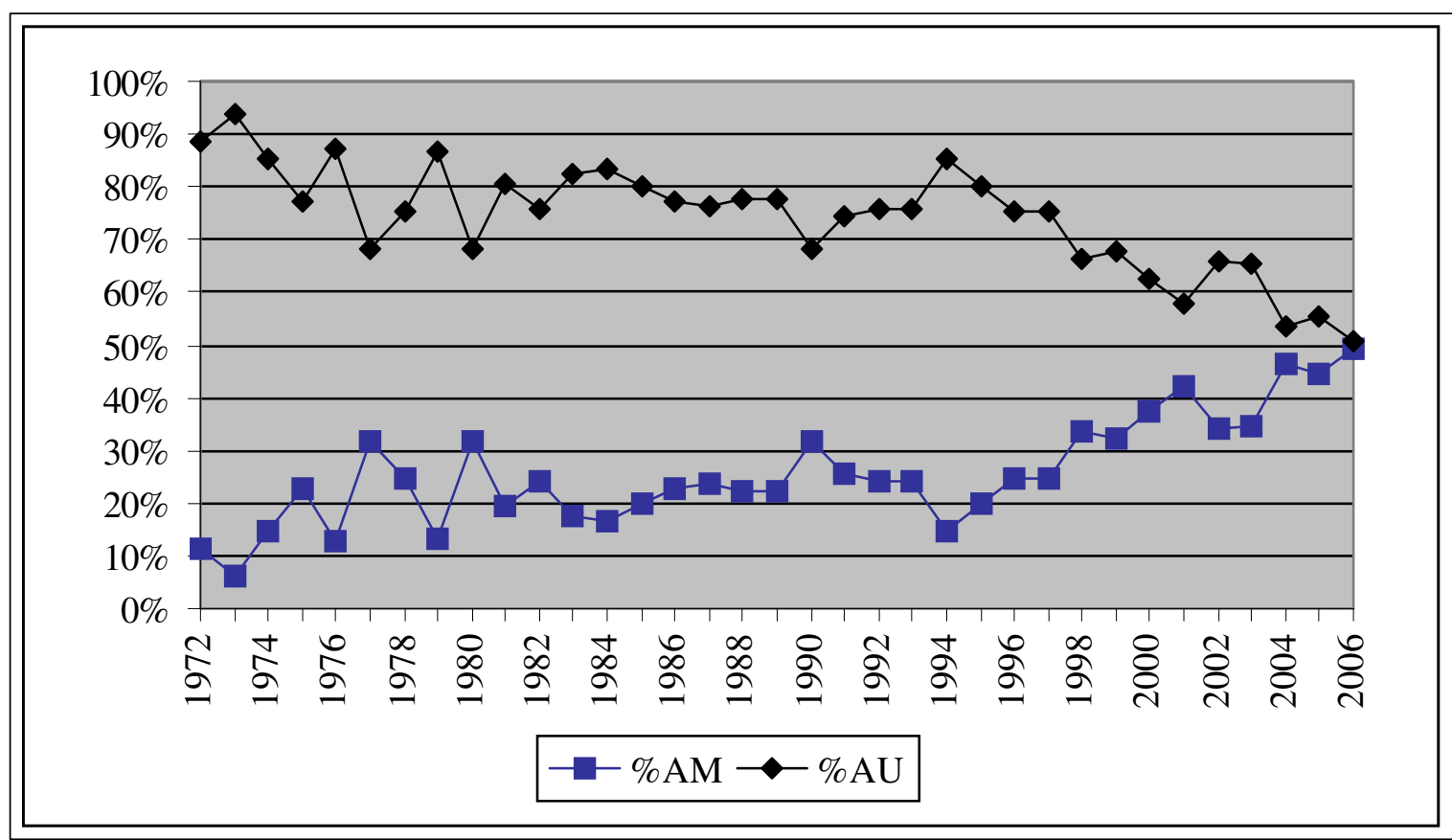

GRÁFICO 2 - Percentual de Artigos Publicados em Periódicos Científicos das Áreas de Informação no Brasil por Tipo de Autoria (1972 2006).

Fonte: Dados da pesquisa.

Nota-se ainda no GRÁF. 2 que o percentual médio anual de artigos em autoria múltipla (\%AM) nos primeiros 10 anos (1972-1981) ficou na 
faixa dos $18 \%$; nos 16 anos seguintes (1982-1997) passou para $22 \%$, nos seis anos seguintes (1998-2003) para 35\%, e finalmente para $46 \%$ nos três últimos anos do estudo (2004-2006), mostrando que as áreas estão alcançando patamares percentuais de autoria múltipla cada vez maiores e em menos tempo.

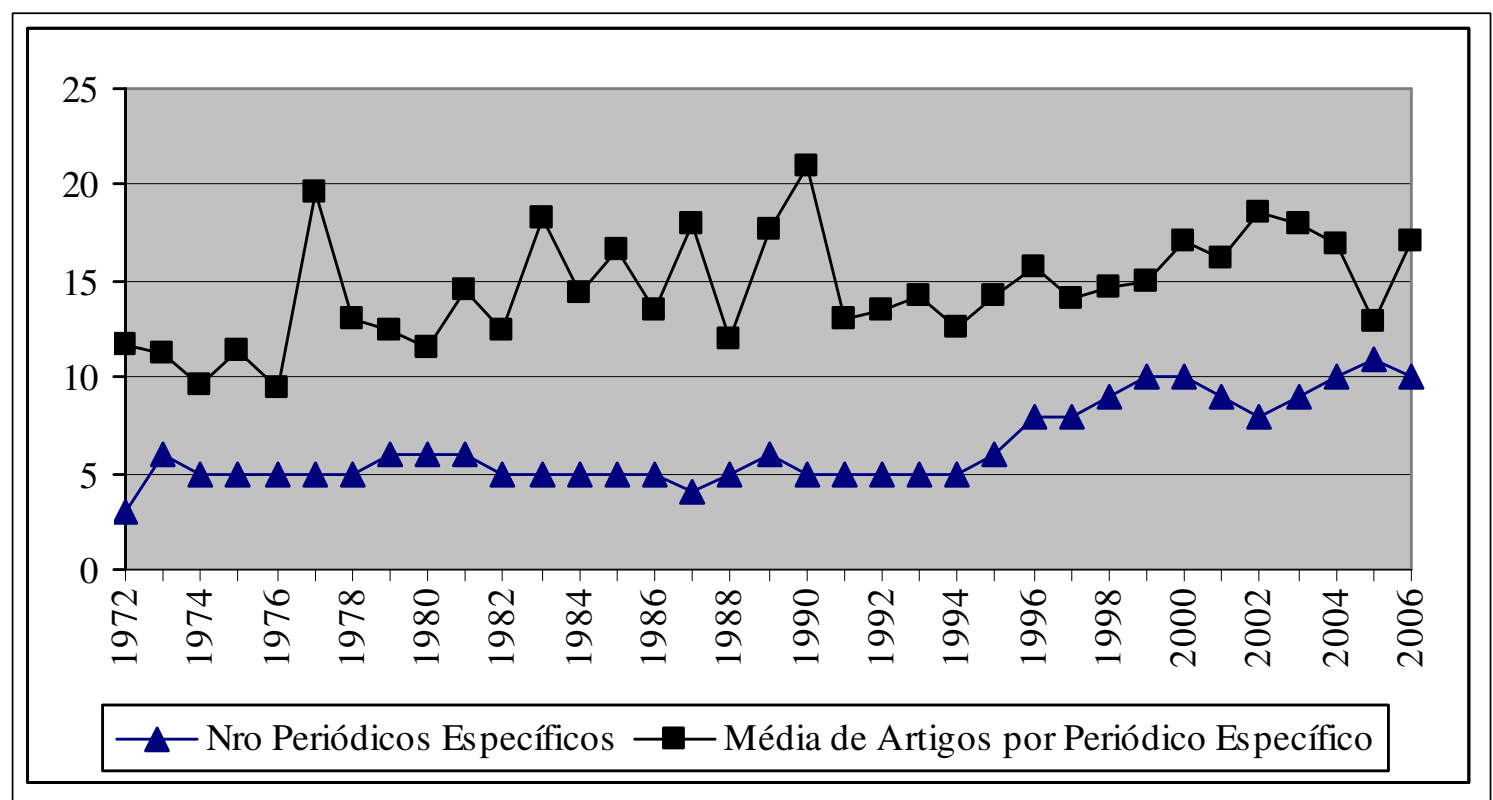

GRÁFICO 3 - Média de Artigos e Número de Periódicos Científicos Específicos das Áreas de Informação no Brasil (1972 - 2006).

Fonte: Dados da pesquisa.

Em relação ao número de periódicos, pode-se observar, na linha inferior do GRÁF. 3, que, no período de 1994 a 1999, o número de títulos de periódicos específicos das áreas de informação, com fascículos publicados, passou de 5 para 10, tendo um crescimento de $100 \%$, mantendo-se a partir daí uma média anual de quase 10 títulos, $(9,63)$ com pelo menos um fascículo publicado por ano (1999-2006). Já o número médio de artigos publicados anualmente em títulos específicos, linha superior do GRÁF. 3, apresenta variações significativas nos períodos de 1976-1978, 1982-1984 e 1988-1991; sofre uma queda a partir de 1991 e vai recuperando-se gradativamente, mantendo valor médio de quase 13,47 artigos/título/ano entre 1991 a 1995, quando passa para o valor médio de 16,00 artigos/título/ano de 1996 a 2006. Quanto à representatividade quantitativa dos títulos de periódicos, as coleções da Ciência da Informação (21,42\%), da Revista da Escola de Biblioteconomia da UFMG/Perspectivas em Ciência da Informação (14,60\%) e da Revista de Biblioteconomia de Brasília (14,73\%) concentram 50,75\% da produção total de artigos (1972-2006). As coleções dos 15 títulos específicos das áreas de informação concentram $90,23 \%$ do total de artigos, sendo que, 
dentre os demais, destacam-se as coleções de Acervo (4,56\% do total) e Revista de Biblioteconomia e Comunicação/Em Questão (2,24\% do total).

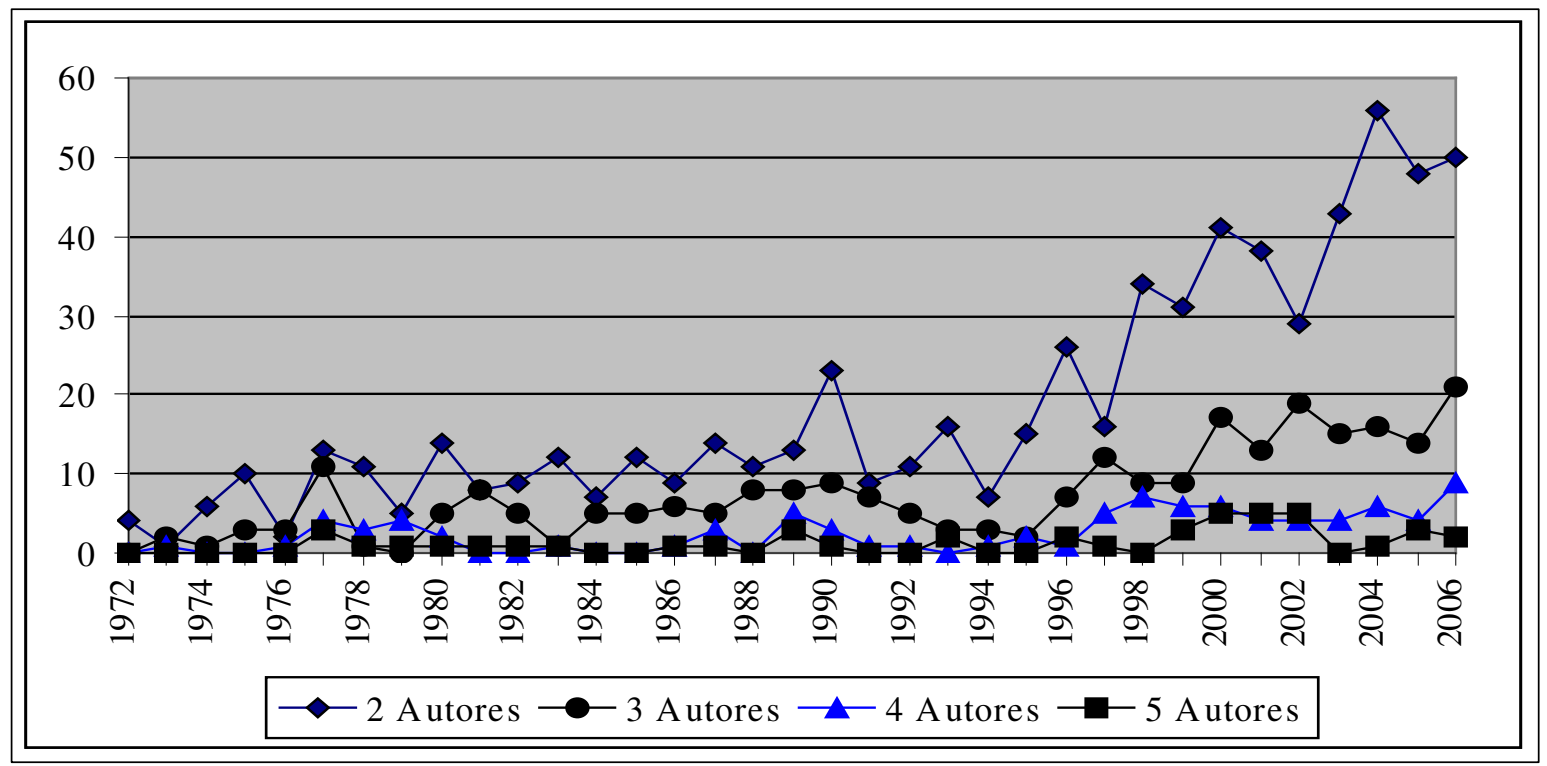

GRÁFICO 4 - Evolução do Número de Artigos em Autoria Múltipla por Número de Autores (1972-1996).

Fonte: Dados da pesquisa.

Em relação ao número de artigos por tipo de autoria múltipla, podese notar no GRÁF. 4, a partir da segunda metade da década de 1990, um crescimento muito acentuado do número de artigos com dois autores e um crescimento menos acentuado do número de artigos com três autores. Já o número de artigos e percentuais de autoria múltipla com quatro ou mais autores têm valores bem mais baixos que os de dois ou três autores, e suas linhas se sobrepõem no GRÁF. 4 e no GRÁF. 5 ao longo de praticamente todo o período estudado.

No GRÁF. 5 há uma grande variação percentual dos artigos em autoria múltipla com dois e três autores dos primeiros anos até a primeira metade da década de 80 (1983-1984). A partir daí a variação diminui substancialmente. Eles representam uma média histórica de 60,64\% e $25,07 \%$ respectivamente; ou seja, cerca de $85 \%$ do total de artigos em autoria múltipla (1972-2006) correspondem a autorias em duplas ou triplas. 


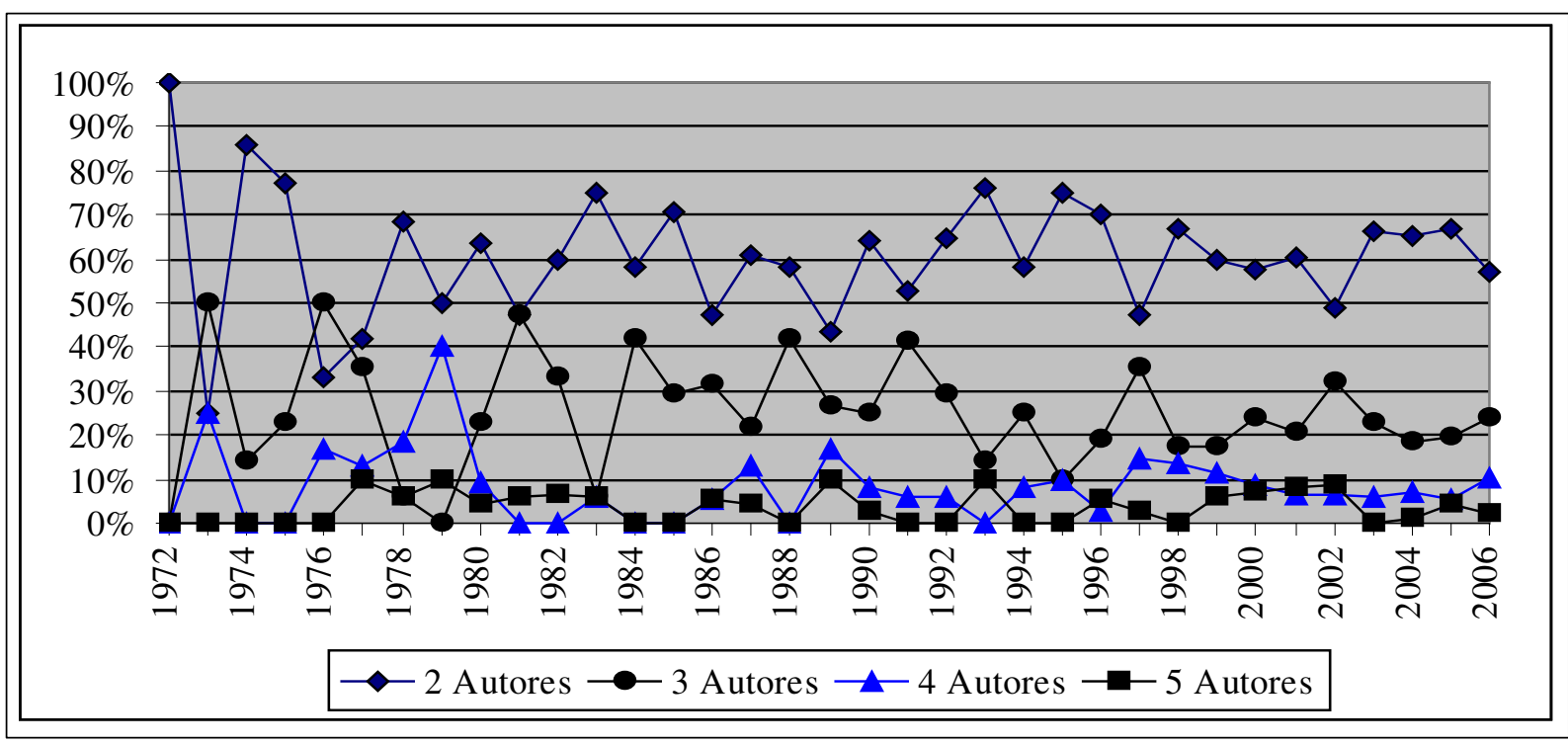

GRÁFICO 5 - Evolução Percentual de Artigos em Autoria Múltipla por Número de Autores (1972-2006).

Fonte:Dados da pesquisa.

Os demais tipos de autoria múltipla, que variam de quatro a vinte e quatro autores, tendem a valores médios anuais inferiores a $10 \%$, principalmente a partir de 2000 (ver GRÁF. 5 e TAB. 1). Neste grupo destacam-se os artigos com autoria múltipla de quatro $(8,44 \%)$ e cinco $(3,61 \%)$ autores, que somam mais de $12 \%$ das autorias múltiplas (19722006). Observa-se ainda (na TAB. 1 e em planilhas não apresentadas) que os percentuais médios entre 2000 e 2006 caem para as autorias múltiplas de dois $(60,28 \%)$, três $(23,11 \%)$ e quatro $(7,21 \%)$ autores e crescem para as autorias múltiplas de cinco (3,61\% para $4,44 \%)$, seis $(1,06 \%$ para $2,23 \%)$ e sete autores, $(0,70 \%$ para $0,85 \%)$ em relação à média histórica geral, o que indica uma tendência consistente de aumento percentual dos artigos com mais de quatro autores.

\section{Conclusões}

Embora o estudo tenha limitações relacionadas com os freqüentes atrasos de publicação dos fascículos, a abrangência da cobertura permite visualizar a evolução da produção de artigos científicos das áreas de informação no Brasil, ainda que com alguma distorção.

De acordo com os dados, a produção de artigos em periódicos científicos brasileiros nas áreas de Arquivologia, Biblioteconomia, Ciência da Informação e Documentação cresceu substancialmente no decorrer das últimas três décadas. Entretanto, tal crescimento não foi uniforme, apresentando grandes variações, especialmente entre 1989 e 1996 . A queda de produção ocorrida entre 1990 e 1994, que pode ser explicada 
em parte pela paralisação da Revista de Biblioteconomia de Brasília de 1991 a 1994, e também pela redução da produção anual em todos os demais periódicos, sugere uma crise no setor editorial científico brasileiro nas áreas de informação.

O crescimento do número de artigos entre 1994 e 1999 pode ser explicado em parte pelo aumento de títulos correntes específicos das áreas de informação, que foi de $100 \%$ no mesmo período, bem como pelo aumento da produtividade anual média por publicação específica, que subiu de 12,60 artigos por título em 1994 para 14,90 artigos por título em 1999.

A produção anual média de artigos científicos nas áreas de informação no Brasil está estabilizada em cerca de 175 artigos por ano desde 2000, distribuída em 15 títulos de periódicos específicos, responsáveis por mais de $90 \%$ dos artigos, e cinco títulos de periódicos não específicos.

O número de periódicos correntes específicos das áreas de informação permaneceu praticamente estável em cerca de cinco títulos durante 21 anos (1974-1994), quando iniciou uma fase de crescimento acelerado, duplicando o número para 10 títulos em apenas cinco anos (1995-1999), e mantendo esta média anual desde então.

A produtividade média dos periódicos específicos tem se mantido num patamar de 16 artigos por ano (1996-2006).

Há um aumento gradativo do número de artigos em autoria múltipla desde o início do período observado (1972-2006), com equilíbrio entre percentuais de autoria única e múltipla em 2006, e provável supremacia da autoria múltipla sobre a única a partir de 2007 ou 2008, no conjunto de periódicos da base ABCID. A maioria dos artigos em autoria múltipla, cerca de $85 \%$ do total (1972-2006), tem dois ou três autores, embora este valor esteja diminuindo: cerca de 83\% (2000-2006) e cerca de 82\% (2001-2006). Por outro lado, aumentaram os percentuais de artigos em autoria múltipla de cinco ou mais autores entre 2000 e 2006.

Os dados apresentados levantam questões que precisam de estudos adicionais mais detalhados, especialmente em relação a fatores intervenientes relacionados com autoria múltipla e suas implicações, à razão das variações nos níveis de produção, percentuais de autoria múltipla e número de títulos de periódicos registrados a partir de meados da década de 1990.

Considerando as afirmações que relacionam autoria múltipla com colaboração em pesquisa (PRICE, 1976), com visibilidade internacional (LETA; CHAIMOVICH, 2002 e OLIVEIRA, 2003), com taxa de impacto (MENEGHINI, 1996), com qualidade e com produtividade (MEADOWS, 1999), os níveis de crescimento da autoria múltipla na literatura científica das áreas de informação, mais especificamente nos 20 títulos de periódicos brasileiros publicados de 1972 a 2006, poderiam indicar crescimento na colaboração entre pesquisadores nas áreas de informação no Brasil, sendo o termo colaboração aqui entendido em seu sentido mais amplo, como sugerido por Katz e Martin (1997). Mas, para verificar esse fato, mais pesquisas devem ser feitas. Também seria interessante 
verificar se teria havido aumento na visibilidade internacional e incremento na qualidade, produtividade e impacto, e, em caso positivo, se seria possível estabelecer associação com o aumento da ocorrência de colaborações. Os resultados deste estudo levantam ainda outras questões, sobre a razão de a ocorrência das autorias múltiplas estarem apresentando taxas crescentes. Seria um reflexo de mudança no padrão de pesquisa, como afirmam alguns autores ${ }^{i i}$, devido à complexidade da realidade atual que demandaria a colaboração de competências diversas? Até que ponto as políticas de fomento que estimulam as parcerias seriam a motivação para o aumento dessa ocorrência? Ou seria um reflexo do desenvolvimento dos cursos de pós-graduação, com o aumento de trabalhos com autoria de orientador e orientando? Futuras pesquisas devem ser dirigidas para essas questões.

\section{Referências}

BOHN, M. C. R. Autores e autoria de periódicos brasileiros de ciência da informação. Encontros Bibli, Florianópolis, n.16, p. 1-19, jul./dez. 2003.

BORGMAN, C. L.; FURNER, J. Scholarly communication and bibliometrics. Annual Review of Information Science and Technology, v.36, p.04-59, 2002.

CRAWFORD, S. Y. Scientific Communication and the growth of Big Science. In: CRAWFORD, S. Y. From print to electronic. [S.I.]: ASIS, 1996, p.01-08.

DE HAAN, J. Authorship patterns in Dutch sociology. Scientometrics, v.39, n.02, p.197-208, jun. 1997.

KATZ, J. S.; MARTIN, B. R. What is research collaboration? Research Policy, v.26, p.01-18, 1997.

KOEHLER, W. Information science as "Little Science": the implications of a bibliometric analysis of the Journal of the American Society for Information Science. Scientometrics, v.51, n.01, p.117-132, 2001.

LETA, J.; CHAIMOVICH, H. Recognition and international collaboration: the Brazilian case. Scientometrics, v.53, n.02, p.325-335, 2002.

LINDSEY citado por MEADOWS, A. J. A comunicação científica. Brasília: Briquet de Lemos, 1999.

MEADOWS, A. J. A comunicação científica. Brasília: Briquet de Lemos, 1999.

MENEGHINI, R. The key role of collaborative work in the growth of Brazilian science in the last ten years. Scientometrics, v. 35, n.03, p.367373, 1996.

MUELLER, S. P. M. O círculo vicioso que prende os periódicos nacionais. DataGramaZero, n.0, artigo 04, dez. 1999. 
MUELleR, S. P. M.; PeCEgueIRO, C. M. P. A. O periódico Ciência da Informação na década de 90: um retrato da área refletido em seus artigos. Ciência da Informação, Brasília, v. 30, n.02, p.47-63, mai./ago. 2001.

OLIVEIRA, H. V. Fatores influentes na visibilidade internacional da comunicação científica de pesquisadores de instituições da Amazônia brasileira. 2003. Tese (Doutorado) - Departamento de Ciência da Informação e Documentação, Universidade de Brasília, Brasília, 2003.

PINHEIRO, L. V. R. Evolução da comunicação científica até as redes eletrônicas e o periódico como instrumento central deste processo. In: CONFERÊNCIA IBEROAMERICANA DE PUBLICAÇÕES ELETRÔNICAS NO CONTEXTO DA COMUNICAÇÃO CIENTÍFICA, 1., 2006, Campo Grande. Anais... Campo Grande: Editora da UNIDERP, 2006.

PRICE, D. J. S. O desenvolvimento da ciência: análise histórica, filosófica, sociológica e econômica. Rio de Janeiro: Livros Técnicos e Científicos, 1976. $98 \mathrm{p}$.

SOUZA, H. B. O reflexo da colaboração científica nos periódicos: uma análise da co-autoria em artigos das áreas de Arquivologia, Biblioteconomia, Ciência da Informação e Documentação publicados no Brasil. 2006. Trabalho de Conclusão de Curso (Graduação em Biblioteconomia) - Departamento de Ciência da Informação e Documentação, Universidade de Brasília, Brasília, 2006.

WORMELL, I. Informetria: explorando bases de dados como instrumentos de análise. Ciência da Informação, Brasília, v.27, n.02, p.210-216, maio/ago. 1998.

$\mathrm{O}$ reconhecimento foi medido pela razão $\mathrm{c} / \mathrm{p}$ onde $\mathrm{c}=$ número de citações $\mathrm{e} \mathrm{p}=$ número de publicações (LETA; CHAIMOVICH, 2002, p.325).

ii Veja por exemplo: COIMBRA JR., Carlos E. A. Editorial. Cad. Saúde Pública, Rio de Janeiro, v. 9, n. 2, 1993. Disponível em: <http://www.scielo.br/scielo.php?script=sci_arttext\&pid=S0102$311 \times 1993000200001 \& \operatorname{lng}=e n \& n r m=i s o>$. Acesso em: 06 Mar 2008; e veja também Luukkonen, T.; Tijseen, R. J. W.; Persson, O.; Sivertsen, G. apud LIMA, R.A.de, VELHO, L. M. S.; FARIA, L. I. L. de. Indicadores bibliométricos de cooperação científica internacional em bioprospecção. Perspectivas em Ciência da Informação, v.12, n.1, 2007. Disponível em http://www.scielo.br/scielo.php?script=sci_arttext\&pid=S1413-

99362007000100005\&lng=e\&nrm=iso\&tlng=e\#top2. Acesso em 6 de março de 2008. 